Research Article

\title{
Strategy Analysis of Selling Model Selection in Vertical Competition Supply Chains: A Game Theoretic Model
}

\author{
Qian Chen $\mathbb{D}^{1},{ }^{1}$ Sen Liu $\mathbb{D}^{2},{ }^{2}$ Lijun Wang $\mathbb{D D}^{1}{ }^{1}$ Zhe Zhang $\mathbb{D}^{3},{ }^{3}$ and Xiaojun He $\mathbb{D}^{2}$ \\ ${ }^{1}$ Business School, Yunnan University of Business Management, Kunming 650106, China \\ ${ }^{2}$ School of Logistics, Yunnan University of Finance and Economics, Kunming 650221, China \\ ${ }^{3}$ School of Economics and Management, Nanjing University of Science \& Technology, Nanjing 210094, China \\ Correspondence should be addressed to Sen Liu; liusencool@163.com and Lijun Wang; wanglijun@yth.cn
}

Received 25 May 2021; Revised 17 July 2021; Accepted 1 September 2021; Published 20 September 2021

Academic Editor: Guiomar Martín-Herrán

Copyright ( $\odot 2021$ Qian Chen et al. This is an open access article distributed under the Creative Commons Attribution License, which permits unrestricted use, distribution, and reproduction in any medium, provided the original work is properly cited.

This paper takes the supply chain perspective to study the choice of selling model for manufacturers and e-tailers. To accomplish our objective, we consider three selling models, including reselling, agency selling, and mixed selling. By comparing and analyzing the equilibrium outcomes of the three selling models, we obtain some beneficial results. These results show that manufacturers and e-tailers cannot manage to make a profit at the same time whether they choose the reselling model or agency selling model. Our results also show that the mixed selling model may improve supply chain performance, as long as the cross-price elasticity is not low. Especially when the cross-price elasticity is comparatively high, a manufacturer and an e-tailer in vertical competition can achieve a profit-Pareto-improving situation, regardless of the market share of the e-tailer.

\section{Introduction}

The development of electronic commerce has led to the rapid expansion of online markets. According to Retail Research, online sales in the U.S. in 2015 amounted to $\$ 349.25$ billion and grew by $14.4 \%$ to $\$ 399.53$ billion in 2016. In 2017, U.S. online sales were forecasted to reach $\$ 459.07$ billion $(+14.9 \%)$ and to grow to $\$ 529.76$ billion in $2018(+15.4 \%)$ [1]. In addition, the Ali Research Institute, in its BRICS national electronic commerce research report, predicted that the total number of online shopping users in the BRICS nations will rise to 1.35 billion by 2022 , accounting for $61 \%$ of online shopping users worldwide, and that the total amount of online retail sales in the BRICS nations will increase to $\$ 3001.6$ billion, accounting for $59 \%$ of total retail sales worldwide [2]. Consequently, different selling models were developed. On the one hand, some e-tailers use agency selling to encourage more manufactures to sell products directly to consumers from the e-tailers' electronic channels. Adopting this model has gradually become a hot topic and aroused widespread concern [3], such as the concern regarding Tmall in China [4]. In the case of agency selling, e-tailers first charge manufacturers an agency fee for each product unit. The manufacturers then set the retail prices for the products and sell the products to consumers by directly using an electronic channel. On the other hand, some e-tailers, such as Jindong and Amazon, adopt reselling in their start-up periods. In the case of reselling, manufacturers first determine the wholesale prices they will charge e-tailers for particular products. The e-tailers then set the retail prices for the products and sell them to consumers. Therefore, the key difference between the two selling models is who sets the retail prices.

With the advent of the mobile commerce era, some e-tailers who adopted reselling in the past began to allow upstream manufacturers to sell products directly through the e-tailers' electronic channels. At the same time, some e-tailers who adopted agency selling in the past also began to purchase products wholesale and sell the products by themselves, which gradually formed a mixed selling model consisting of reselling and agency selling. That is, e-tailers and manufacturers face three choices of selling models, i.e., reselling, agency selling, and mixed selling. For instance, Amazon uses a reselling scheme for only $7 \%$ of the more 
than two million products in its "Electronics" category, and the remaining $93 \%$ are sold under the agency selling scheme [5]. Thus far, agency selling in the e-book market has become more prevalent than reselling in the book industry. For example, five of the Big Six publishers in the United States now sell e-books under the agency selling model through all the major distributors: Amazon, Apple, and Barnes \& Noble. The publishers typically set the e-book selling prices, take $70 \%$ of the sales, and leave $30 \%$ to the e-bookstores [6]. Although agency selling is accepted by an increasing number of e-tailers, reselling continues to prevail as the dominant selling format in some mature digital industries, such as music [7]. Therefore, which selling model should be adopted by e-tailers and manufacturers to maximize their profits has been a key issue, and it is worth the attention of the industrial and academic fields.

In view of the strategic choice of selling model issue, in this paper, we consider a supply chain that includes one manufacturer and one e-tailer. We build three selling models and use the Stackelberg game to obtain equilibrium outcomes. In our models, the manufacturer can distribute its product to the end consumer through the e-tailer or pay agency fees to the e-tailer to use the electronic channel directly. We present and compare the equilibrium outcomes of the three selling models and analyze two main factors in the choice among the three selling models: cross-price elasticity and the market share of the e-tailer. Our study can provide guidance for the coordination of manufacturers and e-tailers in vertical competition regarding the choice of reselling, agency selling, or mixed selling.

The remainder of this paper is organized as follows. The next section reviews the literature from two streams. Section 3 develops three selling models: reselling, agency selling, and mixed selling. Section 4 compares the equilibrium outcomes under the three selling models. Section 5 provides numerical experiments. Section 6 extends the models, and Section 7 draws the conclusion. All proofs of this paper are given in the appendix.

\section{Related Work}

Our research is closely related to two streams of literature: literature on (i) supply chains consisting of electronic retailers and manufacturers and (ii) agency selling in electronic commerce. Next, we describe how our research relates to the literature in these areas.

In an electronic commerce environment, many scholars in the supply chain field focus on the study of supply chains consisting of electronic retailers and manufacturers. In the study of supply chains that include manufacturers and e-retailers, scholars have focused their research on reselling and drop shipping. From the perspective of reselling, specifically, in terms of pricing, Liu et al. [8] developed a stylized model based on the Hotelling model and studied how consistent and inconsistent pricing strategies vary with e-retailers' profits and consumer purchasing decisions. Song et al. [9] studied the optimal pricing of green fresh product supply chain from the perspective of green degree and freshness sensitivity under the background of the game. Saha and Nielsen [10] explored how strategies affect manufacturers' and retailers' product pricing decisions and supply chain performance. In terms of inventory, Cheng et al. [11] considered a supply chain consisting of suppliers and e-retailers on the Internet to study inventory issues in the supply chain. Xu et al. [12] studied inventory replenishment planning problems for retailers with online channels. In terms of returns, Yan and Cao [13] studied the value of product return information to supply chain firms. From the perspective of drop shipping, Chiang and Feng [14] developed EOQ games with pricing and lot-sizing decisions to examine strategic interactions between manufacturers and e-tailers in drop-shipping distribution channels. Yao et al. [15] analyzed the interaction between revenue sharing and order fulfillment quality that occurs in an Internet dropshipping distribution system comprising an e-tailer and a supplier. Gan et al. [16] analyzed commitment-penalty contracts that improve the supply and demand certainty of suppliers in acquiring e-tailers' demand information. Razmi et al. [17] presented a joint model of pricing and online fulfillment assignment for a distribution system in which a supplier sells items through an e-tail channel with the possibility of using substitute items to satisfy customer demands and delivery times. Dennis et al. [18] investigated the impact of the supply chain power structure in terms of market power and retail channel dominance on a manufacturer's optimal distribution channel strategy. However, the above studies only consider reselling and drop shipping between manufacturers and e-tailers and do not involve agency selling between manufacturers and e-tailers.

With the development of e-commerce and the related explorations of entrepreneurs and scholars, agency selling has gradually become popular in the electronic commercial field, and some researchers have begun to focus on the study of this subject. Johnson [19] supposes that agency selling results in revenue share setting by retailers and retail price setting by suppliers to provide a potential explanation for why many online retailers adopt agency selling. Hagiu and Wright [20] studied how much revenue a manufacturer should extract from a retailer and how much control it should grant the agent over decisions that it can monitor. Johnson [21] investigated strategic interactions and market outcomes in the "agency selling" and "reselling" of sales. He found that adopting the agency selling can initially raise prices and raise the profits of rival retailers. Ling et al. [22] proposed a game model to describe the channel competition between hotels and online travel agencies (OTAs) and suggested that a hotel with lower occupancy rates is more inclined to cooperate with an OTA to obtain more profit. Hao and Fan [23] studied the pricing of e-books and e-readers under reselling and agency selling. They showed that prices for e-book readers are lower under agency selling, leading to a higher e-book market share. Santos and Wildenbeest [24] found that e-book prices for titles that were previously sold decreased by 18 percent at Amazon and 8 percent at Barnes \& Noble under agency selling. Tan et al. [25] investigated the strategic impact of agency selling by examining a digital goods supply chain with one supplier and two competing retailers and found that agency selling can coordinate competing retailers by dividing 
coordinated profits into prenegotiated revenue-sharing proportions. Tan and Carrillo [26] created and analyzed a model of vertically differentiated goods to compare and contrast agency selling with reselling. The results show that agency selling outperforms reselling. Lu et al. [27] employed game theory to examine and compare two types of pricing models for electronic books (e-books): reselling and agency selling. They concluded that the benefit from e-book sales may be greater than the loss in physical book sales in agency selling. The above researchers noted the importance of agency selling and showed that agency selling may be an efficient selling model compared to reselling. However, whether agency selling is used depends on the impact of many factors.

To further understand the agency selling model, a considerable number of scholars have studied the factors that influence choosing agency selling, that is, the conditions of adopting agency selling. Kwark et al. [28] discussed when retailers should use upstream pricing schemes, i.e., reselling or agency selling, as strategic tools to benefit from thirdparty information. Hagiu and Wright [29] found that choices of regarding marketplace and reseller mode depend on whether independent suppliers or intermediaries have more important information relevant to the optimal tailoring of marketing activities for each specific product. Dantas et al. [30] characterized and compared equilibrium pricing strategies between reselling model and agency selling model. They showed that the sharing parameter must fall within a specific region to effectively implement agency selling. Abhishek et al. [3] focused on the effects of two main factors on choosing agency selling or reselling in electronic retailing: competition among e-tailers and cross-channel spillovers. Furthermore, Zhang and Zhang [31] discussed and analyzed the different equilibrium results of the demand information strategies of suppliers and e-tailers under reselling and agency selling agreement. However, Tian et al. [32] studied the optimal selling model that could ease the competition between two suppliers selling two substitutable products. It is worth noting that the authors focused on the coordination problem of horizontal competition. Furthermore, Zennyo [33] considered different conditions for adopting reselling model and agency selling model between two competing suppliers-one being a high-volume supplier with potentially high demand and the other being a highvolume supplier with potentially lower demand. Ye et al. [34] studied whether a hotel should cooperate with an independent online travel agency (OTA) to sell rooms and which business model-reselling or agency selling-it should use. They found that the channel and business model choices are closely tied to certain conditions. Zhu and Yao [35] provided a comprehensive comparison between agency selling and reselling under the electronic book market duopoly. They suggested that high wholesale prices led to higher retail prices of e-books and e-readers under reselling. Qin et al. [36] analyzed the interaction between the selling model and logistics service strategy choices by considering agency selling model and other selling models. Feng et al. [37] analyzed the optimal choices of enterprises and luxury rental platforms under the two selling models of reselling and agency selling in the context of the sharing economy. $\mathrm{Pu}$ et al. [38] studied the optimal choice of the three selling strategies of manufacturers: direct selling, reselling, and agency selling. They found that online operating costs and online agency commissions are important factors that affect the manufacturer's selection of selling strategies.

Based on the above papers, we find that (i) although the above studies focus on the conditions of adopting agency selling, they almost do not consider mixed selling which consists of reselling and agency selling between manufacturers and e-tailers and (ii) even though one article innovatively studies the mixed selling model, its specific research object is horizontal competition and coordination between two suppliers under different model selections. In contrast, this paper focuses on the coordination of manufacturers and e-tailers in vertical competition on the choice of reselling, agency selling, or mixed selling. Thus, based on the exploration of reselling and agency selling, this study may offer some further insight into mixed selling, which is currently common in electronic commerce.

\section{The Model}

We consider a supply chain consisting of one manufacturer (he) and one e-tailer (she), in which they can choose among three models to sell the same product: reselling, agency selling, and mixed selling. In the case of reselling represented by JD, the e-tailer can enter into a reselling agreement with the manufacturer, in which case the e-tailer purchases the product from the manufacturer at a fixed wholesale price and decides the retail price. This is similar to brick-and-mortar retailing. In the case of agency selling represented by Taobao, we assume that e-tailers set agency fees under agency selling model, which are driven by business practices. On Taobao e-platform, the e-platform has a large amount of traffic and attracts many upstream manufacturers to settle in. Therefore, under the agency selling model represented by Taobao, the e-tailer is the core enterprise of the whole supply chain, that is, the leader of Stackelberg. Then, the manufacturer can determine the retail price and pay the e-tailer an agency fee per product unit, which is sold to consumers through the electronic channel. There is a key difference between reselling and agency selling: who sets the retail price of a product-in agency selling, the retail price is decided by the manufacturer, whereas in reselling, it is decided by the e-tailer. In mixed selling, the e-tailer charges the manufacturer an agency fee. The manufacturer sets the wholesale price for the e-tailer. Then, they decide retail prices. To facilitate the analysis, we assume that the operating and production costs of the manufacturer and the operating costs of the e-tailer are normalized to zero.

We further make assumptions about the demand model under the reselling model, agency selling model, and mixed selling model. In reselling and agency selling, the electronic channel demand is determined by the market size, self-price elasticity, and retail price. In mixed selling, the manufacturer and the e-tailer's demand will be impacted by the market share of the e-tailer and the cross-price elasticity at the same time.

We list the three cases of the model in Figure 1 and use the backward induction of the Stackelberg method to obtain the equilibrium outcomes of the three models. 


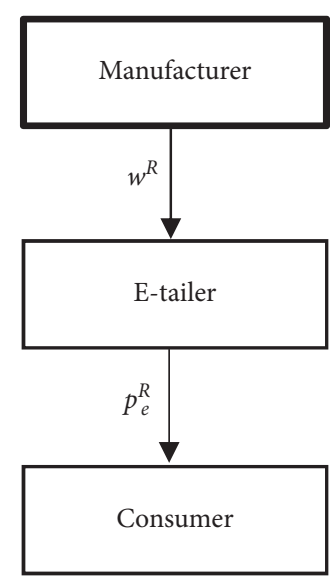

(a)

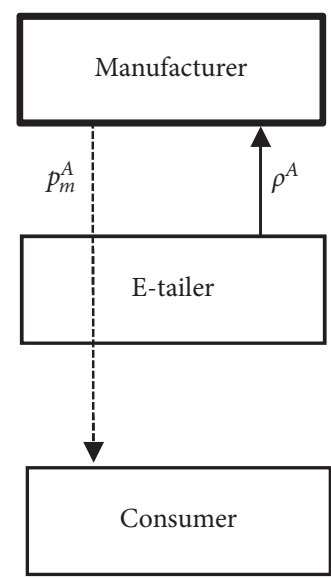

(b)

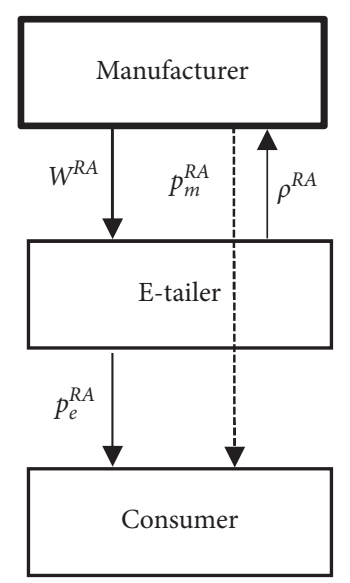

(c)

FIgURE 1: Schematic diagrams showing the channel structures. (a) Reselling. (b) Agency selling. (c) Mixed selling.

Table 1 presents the notions and definitions of the parameters in the proposed model.

3.1. Reselling. The demand function of the e-tailer under reselling is given by

$$
d_{\mathrm{ER}}^{R}=a-b p_{e}^{R} .
$$

We can determine the profits of the manufacturer and the e-tailer by

$$
\begin{aligned}
& \Pi_{M}^{R}=w^{R} d_{\mathrm{ER}}^{R}, \\
& \Pi_{\mathrm{ER}}^{R}=\left(p_{e}^{R}-w^{R}\right) d_{\mathrm{ER}}^{R} .
\end{aligned}
$$

In this configuration, the manufacturer first decides the wholesale price it will charge to the e-tailer and the e-tailer then sets the retail price. Therefore, we obtain Theorem 1 .

Theorem 1. In the reselling model, the optimal prices are given by

$$
\begin{aligned}
& w^{R *}=\frac{a}{2 b} \\
& p_{e}^{R *}=\frac{3 a}{4 b} .
\end{aligned}
$$

Substituting (4) and (5) into (2) and (3), we can determine the optimal profits of the manufacturer and the e-tailer by

$$
\begin{gathered}
\Pi_{M}^{R *}=\frac{a^{2}}{8 b}, \\
\Pi_{\mathrm{ER}}^{R *}=\frac{a^{2}}{16 b} .
\end{gathered}
$$

3.2. Agency Selling. The demand function of the manufacturer under agency selling is given by

$$
d_{M}^{A}=a-b p_{m}^{A}
$$

We can determine the profits of the manufacturer and the e-tailer by

$$
\begin{aligned}
& \Pi_{M}^{A}=\left(p_{m}^{A}-\rho^{A}\right) d_{M}^{A}, \\
& \Pi_{\mathrm{ER}}^{A}=\rho^{A} d_{M}^{A} .
\end{aligned}
$$

In this configuration, the e-tailer first charges the manufacturer an agency fee for each product unit. The manufacturer then sets the retail price and sells the product to consumers by directly using the electronic channel. Therefore, we obtain Theorem 2.

Theorem 2. In the agency selling model, the optimal prices are given by

$$
\begin{gathered}
\rho^{A *}=\frac{a}{2 b}, \\
p_{m}^{A *}=\frac{3 a}{4 b} .
\end{gathered}
$$

From (5) and (12), we can easily find that $p_{e}^{R *}=p_{m}^{A *}$. That is, there is no effect on retail prices whether the reselling or agency selling model is adopted.

Substituting (11) and (12) into (9) and (10), we can determine the optimal profits of the manufacturer and the e-tailer by

$$
\begin{aligned}
& \Pi_{M}^{A *}=\frac{a^{2}}{16 b}, \\
& \Pi_{\mathrm{ER}}^{A *}=\frac{a^{2}}{8 b} .
\end{aligned}
$$

3.3. Mixed Selling. The demand functions of the e-tailer and the manufacturer under mixed selling are given by 
TABLE 1: Notions and definitions.

\begin{tabular}{|c|c|}
\hline Parameters & Definition \\
\hline$d_{\mathrm{ER}}^{R}$ & The electronic channel demand under reselling \\
\hline$d_{M}^{A}$ & The electronic channel demand under agency selling \\
\hline$d_{\mathrm{ER}}^{\mathrm{RA}}$ & The electronic channel demand of the e-tailer under mixed selling \\
\hline$d_{M}^{\mathrm{RA}}$ & The electronic channel demand of the manufacturer under mixed selling \\
\hline$a$ & The market size \\
\hline$\theta$ & The market share of the e-tailer \\
\hline$b$ & The self-price elasticity coefficient of demand \\
\hline$\lambda$ & The cross-price elasticity coefficient of demand \\
\hline Decision variables & Definition \\
\hline$w^{R}$ & Wholesale price under reselling \\
\hline$w^{\mathrm{RA}}$ & Wholesale price under mixed reselling \\
\hline$\rho^{A}$ & Agency fee of the platform under agency selling \\
\hline$\rho^{\mathrm{RA}}$ & Agency fee of the platform under mixed selling \\
\hline$p_{e}^{R}$ & E-tail price determined by the e-tailer under reselling \\
\hline$p_{m}^{A}$ & E-tail price determined by the manufacturer under agency selling \\
\hline$p_{e}^{\mathrm{RA}}$ & E-tail price determined by the e-tailer under mixed selling \\
\hline$p_{m}^{\mathrm{RA}}$ & E-tail price determined by the manufacturer under mixed selling \\
\hline
\end{tabular}

$$
\begin{aligned}
& d_{\mathrm{ER}}^{\mathrm{RA}}=\theta a-b p_{e}^{\mathrm{RA}}+\lambda p_{m}^{\mathrm{RA}}, \\
& d_{M}^{\mathrm{RA}}=(1-\theta) a-b p_{m}^{\mathrm{RA}}+\lambda p_{e}^{\mathrm{RA}}
\end{aligned}
$$

We can determine the profits of the manufacturer and the e-tailer by

$$
\begin{aligned}
& \Pi_{M}^{\mathrm{RA}}=\left(p_{m}^{\mathrm{RA}}-\rho^{\mathrm{RA}}\right) d_{M}^{\mathrm{RA}}+w^{\mathrm{RA}} d_{\mathrm{ER}}^{\mathrm{RA}}, \\
& \Pi_{\mathrm{ER}}^{\mathrm{RA}}=\rho^{\mathrm{RA}} d_{M}^{\mathrm{RA}}+\left(p_{e}^{\mathrm{RA}}-w^{\mathrm{RA}}\right) d_{\mathrm{ER}}^{\mathrm{RA}} .
\end{aligned}
$$

In this configuration, the e-tailer first charges the manufacturer an agency fee for each product unit. Then, the manufacturer sets the wholesale price for the e-tailer. Finally, the e-tailer determines the retail price in the reselling channel, and the manufacturer determines the retail price in the agency selling channel at the same time. Therefore, we obtain Theorem 3.

Theorem 3. In the mixed selling model, the optimal prices are given by

$$
\begin{aligned}
\rho^{\mathrm{RA} *} & =\frac{a}{2\left(8 b^{2}+\lambda^{2}\right)(b+\lambda)(b-\lambda)} K_{1}, \\
w^{\mathrm{RA} *} & =\frac{a\left[\theta\left(2 b^{2}-\lambda^{2}\right)+b \lambda(1-\theta)\right]}{4 b(b+\lambda)(b-\lambda)}, \\
p_{e}^{\mathrm{RA} *} & =\frac{a}{4 b(b+\lambda)(b-\lambda)\left(8 b^{2}+\lambda^{2}\right)} K_{2}, \\
p_{m}^{\mathrm{RA} *} & =\frac{a}{4(b+\lambda)(b-\lambda)\left(8 b^{2}+\lambda^{2}\right)} K_{3},
\end{aligned}
$$

where $K_{1}=8(1-\theta) b^{3}+6 b^{2} \lambda \theta+\lambda^{2}(1-\theta) b+3 \lambda^{3} \theta, \quad K_{2}=$ $24 b^{4} \theta+24 \lambda(1-\theta) b^{3}+2 b^{2} \lambda^{2} \theta+3 \lambda^{3}(1-\theta) b+\lambda^{4} \theta$, and $K_{3}$ $=24(1-\theta) b^{3}+26 b^{2} \lambda \theta+3 \lambda^{2}(1-\theta) b+\lambda^{3} \theta . \quad$ Substituting (19)-(22) into (17) and (18), we can determine the optimal profits of the manufacturer and the e-tailer by

$$
\begin{aligned}
\Pi_{M}^{\mathrm{RA} *} & =\frac{a^{2}}{16 b(b+\lambda)(b-\lambda)\left(8 b^{2}+\lambda^{2}\right)^{2}} K_{4}, \\
\Pi_{\mathrm{ER}}^{\mathrm{RA} *} & =\frac{a^{2}}{8 b(b+\lambda)(b-\lambda)\left(8 b^{2}+\lambda^{2}\right)} K_{5},
\end{aligned}
$$

where $K_{4}=64\left(3 \theta^{2}-2 \theta+1\right) b^{6}+160 \lambda \theta(1-\theta) b^{5}+4 \lambda^{2}\left(\theta^{2}-\right.$ $8 \theta+4) b^{4}+4 \lambda^{3} \theta(1-\theta) b^{3}+\lambda^{4}\left(-35 \theta^{2}-2 \theta+1\right) b^{2}+2 \lambda^{5}(1-$ $\theta) b+\lambda^{6} \theta$ and $K_{5}=4\left(3 \theta^{2}-4 \theta+2\right) b^{4}+12 \lambda \theta(1-\theta) b^{3}+$ $\lambda^{2}\left(5 \theta^{2}-2 \theta+1\right) b^{2}+6 \lambda^{3} \theta(1-\theta) b+\lambda^{4} \theta^{2}$.

\section{Comparison}

To analyze the condition of adopting reselling, agency selling, or mixed selling, we compare the equilibrium outcomes of the three models and obtain several propositions.

By comparing the wholesale price under the reselling model $\left(w^{R *}\right)$ with the wholesale price under the mixed selling model $\left(w^{\mathrm{RA} *}\right)$, we can get the following proposition.

\section{Proposition 1}

(i) If $\lambda_{1} \leq \lambda<b$ or $0<\lambda<\lambda_{1}$ and $\theta>\theta_{1}$, then $w^{R A *}>w^{R *}$

(ii) If $0<\lambda<\lambda_{1}$ and $0<\theta<\theta_{1}$, then $w^{R A *} \leq w^{R *}$,

where $\lambda_{1}=(\sqrt{17}-1) b / 4, \quad \theta_{1}=\left(\left(2 b^{2}-b \lambda-2 \lambda^{2}\right) /(2 b+\lambda)\right.$ $(b-\lambda))$.

Proposition 1 implies that if the cross-price elasticity is comparatively high or not comparatively high and the market share of the e-tailer is high enough, the wholesale price is higher under mixed selling than reselling. Otherwise, 
the wholesale price is lower under mixed selling. Condition (ii) indicates that the basic demand of the retail channel is relatively low $\left(0<\theta<\theta_{1}\right)$, and the wholesale price is lower, in the RA model. Low basic demand can be interpreted as a small audience, so the manufacturer will reduce shipping prices to improve product competitiveness. In contrast, if the audience is large, the manufacturer has confidence that there will be little impact on total demand even if the shipping prices increase, and the results are as (i) in Proposition 1.

By comparing the optimal retail price set by the manufacturer under the agency selling model with the optimal retail price set by the manufacturer under the mixed selling model $\left(p_{m}^{A *}\right.$ and $\left.p_{m}^{\mathrm{RA} *}\right)$ and comparing the optimal retail price set by the e-tailer under the reselling model with the optimal retail price set by the e-tailer under the mixed selling model $\left(p_{e}^{R *}\right.$ and $\left.p_{e}^{\mathrm{RA} *}\right)$, we can get the following proposition.

Proposition 2. $\lambda_{2} \in(0.60 b, 0.61 b)$ exists and is a rational root of $-3 \lambda^{4}-b \lambda^{3}-21 b^{2} \lambda^{2}-26 b^{3} \lambda+24 b^{4}=0$.

(i) If $\lambda_{2} \leq \lambda<b$ or $0<\lambda<\lambda_{2}$ and $0<\theta \leq \theta_{2}$, then $p_{m}^{R A *} \geq p_{m}^{A *}$; otherwise, if $0<\lambda<\lambda_{2}$ and $\theta>\theta_{2}$, then $p_{m}^{R A *}<p_{m}^{A *}$

(ii) If $((\sqrt{5}-1) / 2) b \leq \lambda<b$ or $0<\lambda<((\sqrt{5}-1) / 2) b$ and $\theta \geq \theta_{3}$, then $p_{e}^{R A *} \geq p_{e}^{R *}$; otherwise, if $0<\lambda<$ $((\sqrt{5}-1) / 2) b$ and $0<\theta<\theta_{3}$, then $p_{e}^{R A *}<p_{e}^{R *}$,

where $\theta_{2}=\left(3 \lambda^{2}\left(8 b^{2}+\lambda^{2}\right) /\left(b(b-\lambda)\left(24 b^{2}-2 b \lambda+\lambda^{2}\right)\right)\right), \theta_{3}$ $=\left(3\left(8 b^{2}+\lambda^{2}\right)\left(b^{2}-b \lambda-\lambda^{2}\right)\right) /\left((b-\lambda)\left(24 b^{3}+2 b \lambda^{2}-\lambda^{3}\right)\right)$.

Proposition 2 implies that if either the cross-price elasticity is high or it is not high but the market share of the e-tailer is not high, then the retail price determined by the manufacturer is higher under mixed selling than under agency selling. Otherwise, the retail price determined by the manufacturer is lower under mixed selling. Proposition 2 also implies that if either the cross-price elasticity is high or it is not high but the market share of the e-tailer is not low, then the retail price determined by the e-tailer is higher under mixed selling than under reselling. Otherwise, the retail price determined by the e-tailer is lower under mixed selling.

By comparing the agency fee under the agency selling model $\left(\rho^{A *}\right)$ with the agency fee under the mixed selling model $\left(\rho^{\mathrm{RA} *}\right)$, we can get the following proposition.

Proposition 3. $\lambda_{3} \in(0.65 b, 0.66 b)$ exists and is a rational root of $-\lambda^{3}-b \lambda^{2}-5 b^{2} \lambda+4 b^{3}=0$.

(i) If $\lambda_{3} \leq \lambda<b$ or $0<\lambda<\lambda_{3}$ and $0<\theta \leq \theta_{4}$, then $\rho^{R A *} \geq \rho^{A *}$

(ii) If $0<\lambda<\lambda_{3}$ and $\theta>\theta_{4}$, then $\rho^{R A *}<\rho^{A *}$,

where $\theta_{4}=\lambda^{2}\left(8 b^{2}+\lambda^{2}\right) /\left(b(b-\lambda)\left(8 b^{2}+2 b \lambda+3 \lambda^{2}\right)\right)$.

Proposition 3 implies that if either the cross-price elasticity is high or it is not high but the market share of the e-tailer is not comparatively high, then the agency fee is higher under mixed selling than under agency selling. Otherwise, the agency fee is lower under mixed selling. The reason for this result may be that when the cross-price elasticity is high or not high and the market share of the e-tailer is not comparatively high, the retail prices determined by the manufacturer and the e-tailer under mixed selling are high. Thus, the agency fee may be higher under mixed selling.

Next, we will compare the profits of the manufacturer and the e-tailer under the three models. Specifically, by comparing the profits of the manufacturer under the reselling model with the profits of the manufacturer under the agency selling model $\left(\Pi_{M}^{R *}\right.$ and $\left.\Pi_{M}^{A *}\right)$ and comparing the profits of the e-tailer under the reselling model with the profits of the e-tailer under the agency selling model $\left(\Pi_{\mathrm{ER}}^{R *}\right.$ and $\Pi_{\mathrm{ER}}^{A *}$ ), we can get the following proposition.

\section{Proposition 4}

$$
\begin{aligned}
& \text { (i) } \Pi_{M}^{R *}>\Pi_{M}^{A *} \\
& \text { (ii) } \Pi_{E R}^{A *}>\Pi_{E R}^{R *}
\end{aligned}
$$

Proposition 4 shows that the manufacturer's profit in the reselling model is greater than its profit in the agency selling model under any conditions, but the e-tailer's profit in the agency selling model is greater than its profit in the reselling model. The reason for this result may be that the manufacturer is the Stackelberg leader in the reselling arrangement because he decides the wholesale price first, whereas he is a Stackelberg follower in the agency arrangement because the e-tailer decides the agency fee first.

From Proposition 4, we find that the supply chain members cannot obtain Pareto improvement under either reselling or agency selling. Therefore, by comparing the profits of the manufacturer under the reselling model with the profits of the manufacturer under the mixed selling model $\left(\Pi_{M}^{R *}\right.$ and $\left.\Pi_{M}^{\mathrm{RA} *}\right)$, we can get the following proposition.

Proposition 5. $\lambda_{4} \in(0.721 b, 0.722 b)$ exists and is a rational root of $\lambda^{6}+2 b \lambda^{5}-35 b^{2} \lambda^{4}-4 b^{3} \lambda^{3}-4 b^{4} \lambda^{2}-160 b^{5} \lambda+$ $128 b^{6}=0$. If the following conditions can be set up, then $\Pi_{M}^{R A *} \geq \Pi_{M}^{R *}$.

(i) $\lambda_{4} \leq \lambda<b$

(ii) $(\sqrt{2} / 2) b<\lambda<\lambda_{4}$ and $\left(0, \theta_{6}\right] \cup t\left[\theta_{5}, 1\right)$

(iii) $0<\lambda \leq(\sqrt{2} / 2) b$ and $\left[\theta_{5}, 1\right)$,

where $\quad \theta_{5}=-\left(B_{1}-\sqrt{B_{1}^{2}-4 A_{1} C_{1}}\right) / 2 A_{1}, \quad \theta_{6}=-\left(\left(B_{1}+\right.\right.$ $\left.\left.\sqrt{B_{1}^{2}-4 A_{1} C_{1}}\right) / 2 A_{1}\right), \quad A_{1}=(b-\lambda)(2 b+\lambda) \times\left(96 b^{4}-32 b^{3}\right.$ $\left.\lambda+34 b^{2} \lambda^{2}-b \lambda^{3}-\lambda^{4}\right), \quad B_{1}=-2 b(b-\lambda)(2 b-\lambda)(4 b+\lambda)$ $\left(8 b^{2}+\lambda^{2}\right)$, and $C_{1}=-\left(b^{2}-2 \lambda^{2}\right)\left(8 b^{2}+\lambda^{2}\right)^{2}$.

Proposition 5 implies that the manufacturer will choose mixed selling in some situations. These situations include the following: (i) the cross-price elasticity is comparatively high; (ii) the cross-price elasticity is comparatively high and the 
market share of the e-tailer is low enough or not low; and (iii) the cross-price elasticity is not comparatively high, and the market share of the e-tailer is not low.

Next, by comparing the profits of the e-tailer under the agency selling model with the profits of the e-tailer under the mixed selling model $\left(\Pi_{\mathrm{ER}}^{A *}\right.$ and $\left.\Pi_{\mathrm{ER}}^{\mathrm{RA} *}\right)$, we can get the following proposition.

Proposition 6. $\lambda_{5} \in(0.606 b, 0.607 b)$ exists and is a rational root of $\lambda^{6}-6 b \lambda^{5}+5 b^{2} \lambda^{4}-60 b^{3} \lambda^{3}+20 b^{4} \lambda^{2}-96 b^{5}$ $\lambda+64 b^{6}=0$. If the following conditions can be set up, then $\Pi_{E R}^{R A *} \geq \Pi_{E R}^{A *}$.

$$
\begin{aligned}
& \text { (i) } \lambda_{5} \leq \lambda<b \\
& \text { (ii) }((\sqrt{3 \sqrt{17}-11}) / 2) b<\lambda<\lambda_{5} \text { and }\left(0, \theta_{8}\right] \cup t\left[\theta_{7}, 1\right) \\
& \text { (iii) } 0<\lambda \leq((\sqrt{3 \sqrt{17}-11}) / 2) b \text { and }\left(0, \theta_{8}\right] \text {, }
\end{aligned}
$$

where $\theta_{7}=-\left(\left(B_{2}-\sqrt{B_{2}^{2}-4 A_{2} C_{2}}\right) / 2 A_{2}\right), \quad \theta_{8}=-\left(\left(B_{2}+\right.\right.$ $\left.\left.\sqrt{B_{2}^{2}-4 A_{2} C_{2}}\right) / 2 A_{2}\right), \quad A_{2}=(b-\lambda)\left(12 b^{3}+5 b \lambda^{2}-\lambda^{3}\right), \quad B_{2}=$ $-2 b(b-\lambda)\left(8 b^{2}+2 b \lambda+3 \lambda^{2}\right)$, and $C_{2}=8 b^{2} \lambda^{2}+\lambda^{4}$.

Proposition 6 implies that the e-tailer will choose mixed selling in some situations. These situations include following: (i) the cross-price elasticity is high; (ii) the cross-price elasticity is moderate, and the market share of the e-tailer is low or high enough; and (iii) the cross-price elasticity is not high, and the market share of the e-tailer is low.

Furthermore, from Propositions 5 and 6, we can get the conditions that the manufacturer' profit under the mixed selling model is better than the reselling model (i.e., $\Pi_{M}^{\mathrm{RA} *} \geq \Pi_{M}^{R *}$ ), and the e-tailer' profit under the mixed selling model is better than the agency selling model (i.e., $\Pi_{\mathrm{ER}}^{\mathrm{RA} *} \geq \Pi_{\mathrm{ER}}^{A *}$ ), as shown in the following proposition.

Proposition 7. If the following conditions can be set up, then $\Pi_{M}^{R A *} \geq \Pi_{M}^{R *}, \Pi_{E R}^{R A *} \geq \Pi_{E R}^{A *}$.
(i) $\lambda_{4} \leq \lambda<b$
(ii) $(\sqrt{2} / 2) b<\lambda<\lambda_{4}$ and $\left(0, \theta_{6}\right] \cup t\left[\theta_{5}, 1\right)$
(iii) $\lambda_{5}<\lambda<(\sqrt{2} / 2) b$ and $\left[\theta_{5}, 1\right)$
(iv) $((\sqrt{3 \sqrt{17}-11}) / 2) b<\lambda<\lambda_{5}$ and $\left[\theta_{7}, 1\right)$

Proposition 7 shows that supply chain members choosing mixed selling can achieve win-win outcomes in some situations. These situations include the following: (i) the cross-price elasticity is comparatively high; (ii) the crossprice elasticity is comparatively high, and the market share of the e-tailer is low enough or not low; (iii) the cross-price elasticity is high, and the market share of the e-tailer is not low; and (iv) the cross-price elasticity is moderate, and the market share of the e-tailer is high enough.

\section{Numerical Examples}

In this section, by conducting several numerical experiments, we focus on the impact of cross-price elasticity and the e-tailer's market share on the choice of selling model for the supply chain members. Let $a=100$ and $b=1$ [3]; we assume that $\Delta \Pi_{M}^{*}=\Pi_{M}^{\mathrm{RA} *}-\Pi_{M}^{R *}$ and $\Delta \Pi_{\mathrm{ER}}^{*}=\Pi_{\mathrm{ER}}^{\mathrm{RA} *}-\Pi_{\mathrm{ER}}^{A *}$, as summarized in Figures $2-4$.

From Figure 2, we can easily find that if the cross-price elasticity is comparatively high $\left(\lambda=0.8>\lambda_{4}=0.7216\right)$, no matter how the market share of the e-tailer changes, the choice of mixed selling model is more beneficial for the manufacturer. We can also find that if the cross-price elasticity is comparatively high $\left(\lambda=0.72<\lambda_{4}=0.7216\right.$ and $\left.\lambda=0.7<\lambda_{4}=0.7216\right)$ and the market share of the e-tailer is not low $\left(\theta>\theta_{5}=0.4707\right)$, the manufacturer still prefers to choose the mixed selling model. In addition, when the crossprice elasticity is comparatively high $\left(0.707<\lambda=0.72<\lambda_{4}=\right.$ $0.7216)$ and the market share of the e-tailer is low enough $\left(\theta<\theta_{6}=0.1378\right)$, choosing the mixed selling model is the optimal choice for the manufacturer. However, unless the cross-price elasticity is high enough or if the market share of the e-tailer is low $\left(\theta_{6}=0.1378<\theta<\theta_{5}=0.4707\right)$, the manufacturer will choose the reselling model.

From Figure 3, we can easily find that if the cross-price elasticity is high $\left(\lambda=0.8>\lambda_{5}=0.6064\right)$, no matter how the market share of the e-tailer changes, the choice of mixed selling model is more beneficial for the e-tailer. We can also find that if the cross-price elasticity is moderate $\left(\lambda=0.6<\lambda_{5}=0.6064\right.$ and $\left.\lambda=0.57<\lambda_{5}=0.6064\right)$ and the market share of the e-tailer is low $\left(\theta<\theta_{8}=0.4389\right)$, the e-tailer still prefers to choose the mixed selling model. In addition, when the cross-price elasticity is moderate $\left(0.585<\lambda=0.6<\lambda_{5}=0.6064\right)$ and the market share of the e-tailer is high enough $\left(\theta>\theta_{7}=0.8940\right)$, choosing the mixed selling model is the optimal choice for the e-tailer. However, unless the cross-price elasticity is high enough or if the market share of the e-tailer is not low enough or not high enough $\left(\theta_{8}=0.4389<\theta<\theta_{7}=0.8940\right)$, the e-tailer will choose the agency selling model.

From Figure 4, we can easily find that if the cross-price elasticity is comparatively high $\left(\lambda=0.8>\lambda_{4}=0.7216\right)$, no matter how the market share of the e-tailer changes, the choice of mixed selling model is more beneficial for the manufacturer and the e-tailer. We can also find that if the cross-price elasticity is not high enough $\left(\lambda=0.7<\lambda_{4}=0.7216\right.$ and $\left.\lambda=0.6<\lambda_{5}=0.6064\right)$ and the market share of the e-tailer is high enough $\left(\theta>\theta_{7}=0.8940\right)$, the manufacturer and the e-tailer still prefer to choose the mixed selling model. In addition, when the cross-price elasticity is comparatively high $\left(\lambda_{5}=0.6064<\lambda=\right.$ $\left.0.72<\lambda_{4}=0.7216\right)$ and the market share of the e-tailer is not low $\left(\theta>\theta_{5}=0.4707\right)$, choosing the mixed selling model is the optimal choice for both sides. Besides, the mixed selling model can improve profits of the manufacturer and the e-tailer when the cross-price elasticity is not comparatively high $\left(\lambda=0.72<\lambda_{4}=0.7216\right)$ and the market share of the e-tailer is low enough $\left(\theta<\theta_{6}=0.1378\right)$.

\section{Discussion}

6.1. Findings. In this paper, we consider a supply chain consisting of two members--a manufacturer and an e-tailer--and identify the conditions under which they should adopt certain selling models. From Theorems 1 and 2, we 


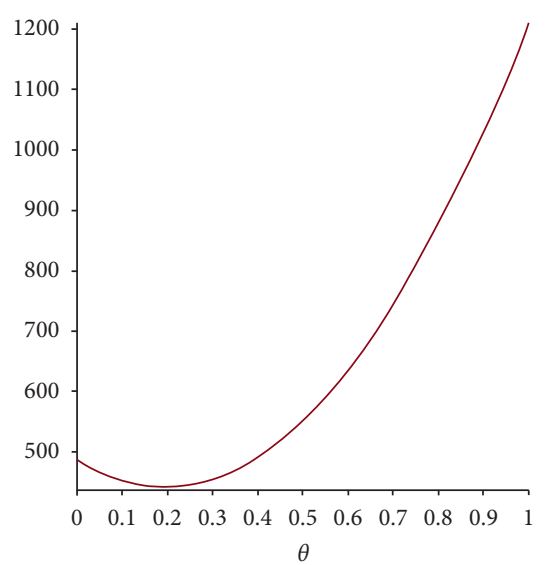

(a)

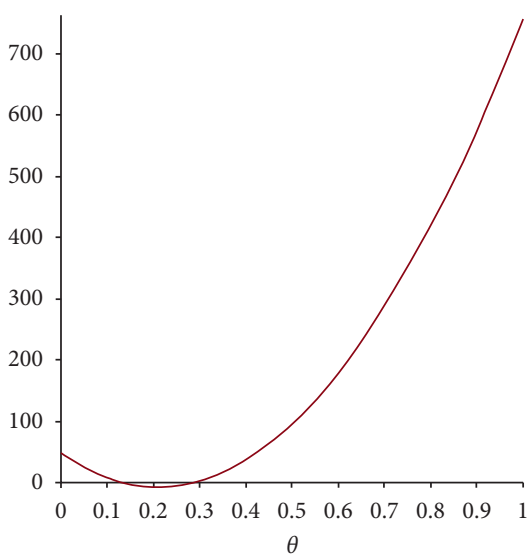

(b)

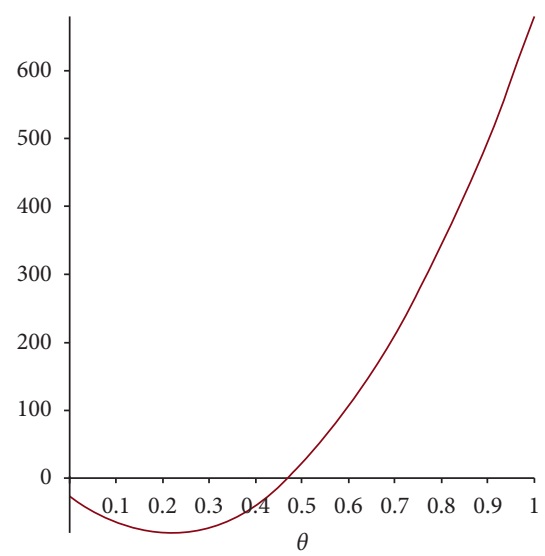

(c)

Figure 2: The impact of $\theta$ on $\Delta \Pi_{M}^{*}$. (a) $\lambda=0.8$. (b) $\lambda=0.72$. (c) $\lambda=0.7$.

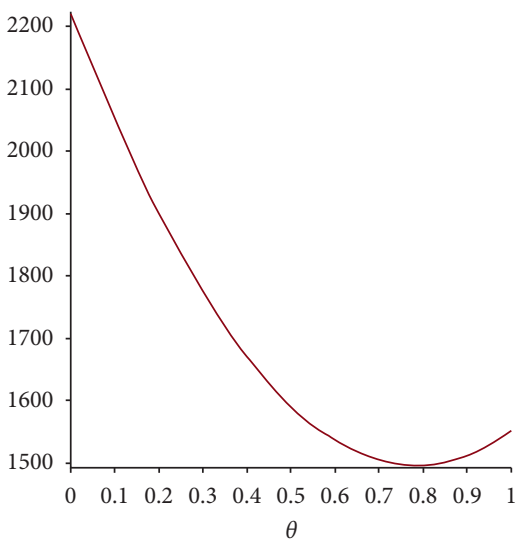

(a)

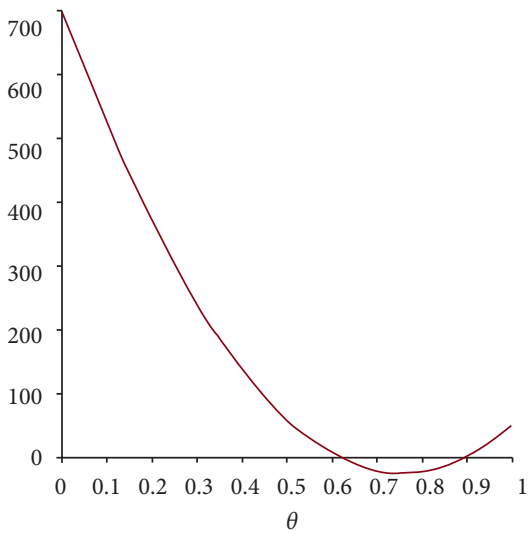

(b)

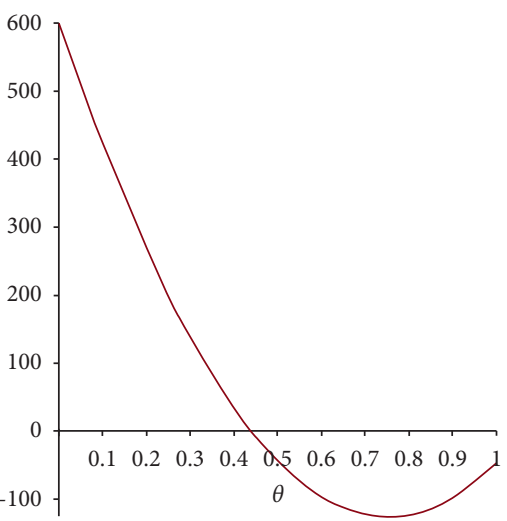

(c)

Figure 3: The impact of $\theta$ on $\Delta \Pi_{\mathrm{ER}}^{*}$. (a) $\lambda=0.8$. (b) $\lambda=0.6$. (c) $\lambda=0.57$.

know that the profits of the manufacturer and the e-tailer are positive in the reselling and agency selling models at the same time, which means that the manufacturer and the e-tailer can both be profitable in the reselling model and agency selling model. Furthermore, by comparing the two models, we find that the manufacturer makes more profits in the reselling model (the manufacturer is the leader of Stackelberg in the reselling model), and the e-tailer makes more profits in the agency selling model (the e-tailer is the leader of Stackelberg in the agency selling model). We further compare the profits of the manufacturer in the mixed selling model and the reselling model and find that the manufacturer's profit level in the mixed selling model is better than the profit level in the reselling model under some certain conditions. Similarly, by comparing the profits of the e-tailer in the mixed selling model and the agency selling model, we are happy to find that the profit level of the e-tailer in the mixed selling model is higher than the profit level in the agency selling model when some certain conditions are satisfied. Combining the conditions in the above two situations, we find that the profits of the manufacturer and the e-tailer can be Pareto improved in the mixed selling model at the same time, that is, in the mixed selling model, supply chain members can increase their profits at the same time under some certain conditions. Therefore, both the manufacturer and the e-tailer are more willing to choose the mixed selling model.

6.2. Theoretical Contributions. First, although the mixed selling may be a more efficient selling format for supply chain members, whether a particular e-tailer or manufacturer should use it or not depends on the cross-price elasticity and the market share of the e-tailer. Specifically, the manufacturer should use mixed selling when the cross-price elasticity is comparatively high or the cross-price elasticity is comparatively high and the market share of the e-tailer is low enough or not low or the cross-price elasticity is not comparatively high and the market share of the e-tailer is not low. The e-tailer should use mixed selling when the cross-price elasticity is high or the cross-price elasticity is moderate and the market share of the e-tailer is low or high enough or the crossprice elasticity is not high and the market share of the e-tailer 


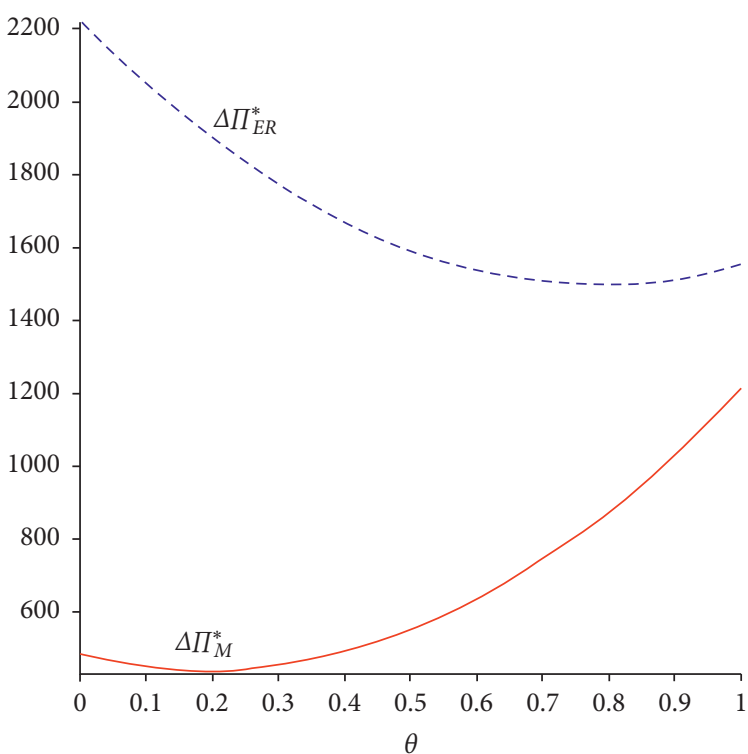

(a)

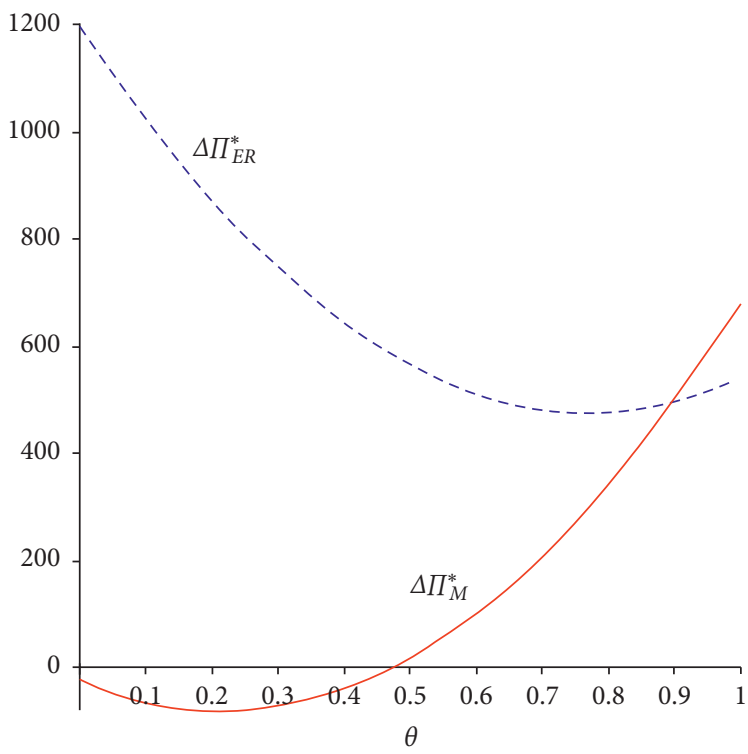

(c)

FIgURE 4: The impact of $\theta$ on $\Delta \Pi_{M}^{*}$ and $\Delta \Pi_{\mathrm{ER}}^{*}$

is low. Furthermore, the mixed selling model can simultaneously increase the profits of the manufacturer and the e-tailer when the cross-price elasticity is comparatively high or the cross-price elasticity is comparatively high and the market share of the e-tailer is low enough or not low or the cross-price elasticity is high and the market share of the e-tailer is not low or the cross-price elasticity is moderate and the market share of the e-tailer is high enough.

Second, we also provide suggestions for setting prices and agency fees. We find that a manufacturer's wholesale price is higher under mixed selling when the cross-price elasticity is comparatively high or not comparatively high and the market share of the e-tailer is high enough. For retail prices, there is no effect on pricing whether reselling or agency selling is adopted. However, retail prices determined

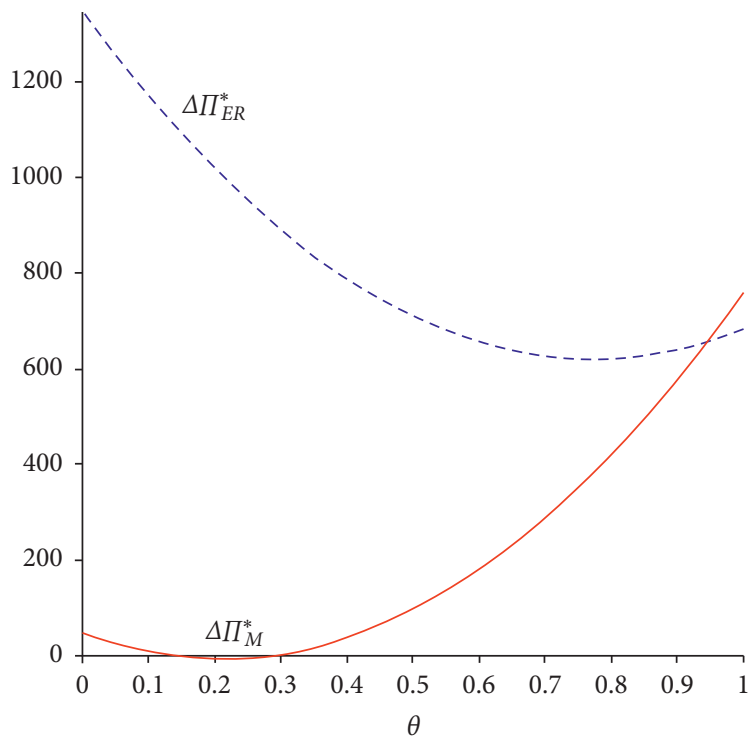

(b)

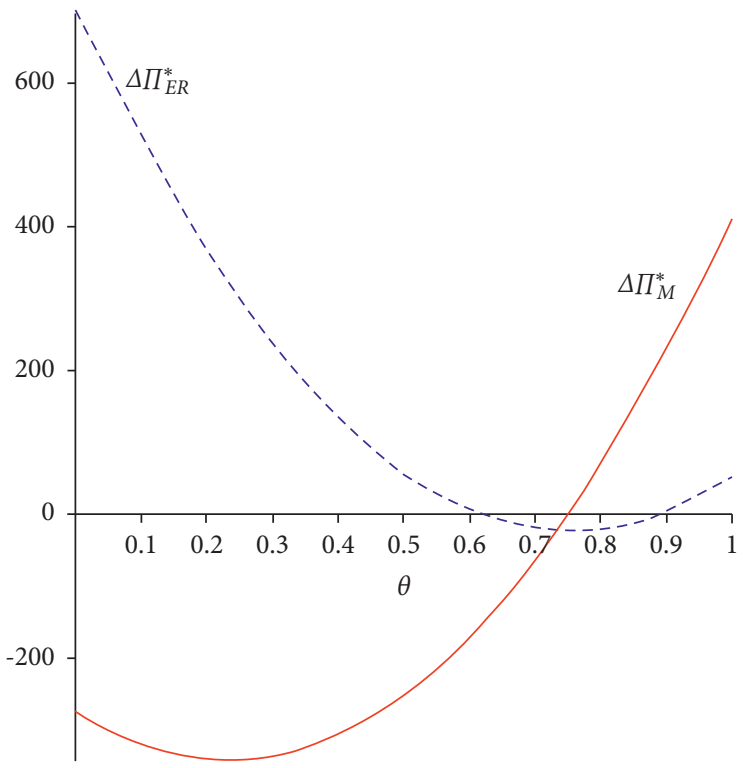

(d)

(a) $\lambda=0.8$. (b) $\lambda=0.72$. (c) $\lambda=0.7$. (d) $\lambda=0.6$.

by the manufacturer are higher under mixed selling when cross-price elasticity is high or not high and the market share of the e-tailer is not high. In addition, retail prices determined by the e-tailer are higher under mixed selling when cross-price elasticity is high or not high and the market share of the e-tailer is not low. Similarly, from the analysis of agency fees, we conclude that when the cross-price elasticity is high or not high and the market share of the e-tailer is not comparatively high, agency fees are higher under mixed selling than under agency selling. Otherwise, agency fees are lower under mixed selling.

6.3. Managerial Insights. First, managers should realize that reselling and agency selling are not undesirable selling 
models. From our equilibrium results, the two models can also make manufacturers and e-tailers profitable in the supply chain. We are just looking for a new selling model that can simultaneously improve the profits of all members of the supply chain. The results prove that the mixed selling model consists of reselling and agency selling can increase the profit level of manufacturers and e-tailers at the same time.

Second, managers should also note that the profit-Pareto-improving situation brought by the mixed selling model is not unconditional. Only when the relevant research factors satisfy some certain conditions, the improvement results we hope will appear. Otherwise, manufacturers and e-retailers are more inclined to choose other selling models. Therefore, managers should evaluate specific business conditions and make scientific decisions under the premise of fully considering the combined effects of multiple factors on choosing different selling models.

6.4. Limitations and Future Work. Our research demonstrates that mixed selling may be a more efficient selling format for the manufacturer and the e-tailer under some conditions. This discovery improves the development and application of agency selling and helps channel participants make better choices regarding selling models. However, the presented model has a few limitations. For instance, there are a number of constraints with the model. First, it considers only one manufacturer and one e-tailer, but the traditional channel is another important type of supply chain. Second, it supposes that the production cost of the manufacturer is normalized to zero. Third, it does not consider the impact of coordination or cooperation mechanisms on the choice of the selling model. Therefore, this paper suggests a few directions for future research at the same time. First, this work can be extended to include a more complex channel structure (the manufacturer, the e-tailer, and the retailer), and it will be interesting to see the results of different selling models when considering the traditional channel. Second, we will further consider the production cost into the model. Last but not least, one interesting future research direction could be on the impact of coordination or cooperation mechanisms on the choice of the selling model.

\section{Conclusion}

In this article, research on channel selling model selection in the field of supply chain is presented, especially related to e-commerce platforms. A literature review of supply chain selling models concepts and applications is provided. This work has further promoted the research dialogue on how selling models are scientifically selected and applied to the selling of supply chain products. We obtain the same conclusion that manufacturers and retailers may be profitable under the reselling model or agency selling model $[31,34,35]$. However, to obtain a selling model that can improve the profits of manufacturers and e-tailers at the same time, we further compare and analyze the reselling model and the agency selling model with the mixed selling model. As a result, we are happy to find that the mixed selling model brings opportunities to improve the profits of supply chain members at the same time under some certain conditions. Therefore, the mixed selling model can allow supply chain members to achieve a profit-Pareto-improving situation and further encourage manufacturers and e-tailers to adopt it under certain conditions.

\section{Appendix}

\section{Proof of Theorem 1}

Substituting (1) into (3), we can obtain

$$
\Pi_{\mathrm{ER}}^{R}=\left(p_{e}^{R}-w^{R}\right)\left(a-b p_{e}^{R}\right)
$$

It is easy to verify that the second derivative of $p_{e}^{R}$ is less than zero. Let the first derivative of $p_{e}^{R}$ be equal to zero; then, we obtain the response function, which is given by

$$
p_{e}^{R}\left(w^{R}\right)=\frac{b w^{R}+a}{2 b} .
$$

Substituting (1) and (A.2) into (2) and finding the first derivative of $w^{R}$ and letting it equal to zero, we can obtain the optimal wholesale price by

$$
w^{R *}=\frac{a}{2 b} \text {. }
$$
by

Substituting (A.3) into (A.2), the optimal price is given

$$
p_{e}^{R *}=\frac{3 a}{4 b} .
$$

\section{Proof of Theorem 2}

Substituting (8) into (9), we can obtain

$$
\Pi_{M}^{A}=\left(p_{m}^{A}-\rho^{A}\right)\left(a-b p_{m}^{A}\right) .
$$

It is easy to verify that the second derivative of $p_{m}^{A}$ is less than zero. Let the first derivative of $p_{m}^{A}$ be equal to zero; then, we obtain the response function, which is given by

$$
p_{m}^{A}\left(\rho^{A}\right)=\frac{b \rho^{A}+a}{2 b}
$$

Substituting (8) and (A.6) into (10) and finding the first derivative of $\rho^{A}$ and letting it equal to zero, we can obtain the optimal agency fee by

$$
\rho^{A *}=\frac{a}{2 b}
$$

Substituting (A.7) into (A.6), the optimal price is given by

$$
p_{m}^{A *}=\frac{3 a}{4 b}
$$




\section{Proof of Theorem 3}

Substituting (15) and (16) into (17) and (18), we can obtain

$$
\begin{aligned}
& \Pi_{M}^{\mathrm{RA}}=\left(p_{m}^{\mathrm{RA}}-\rho^{\mathrm{RA}}\right)\left[(1-\theta) a-b p_{m}^{\mathrm{RA}}+\lambda p_{e}^{\mathrm{RA}}\right]+w^{\mathrm{RA}}\left(\theta a-b p_{e}^{\mathrm{RA}}+\lambda p_{m}^{\mathrm{RA}}\right), \\
& \Pi_{\mathrm{ER}}^{\mathrm{RA}}=\rho^{\mathrm{RA}}\left[(1-\theta) a-b p_{m}^{\mathrm{RA}}+\lambda p_{e}^{\mathrm{RA}}\right]+\left(p_{e}^{\mathrm{RA}}-w^{\mathrm{RA}}\right)\left(\theta a-b p_{e}^{\mathrm{RA}}+\lambda p_{m}^{\mathrm{RA}}\right) .
\end{aligned}
$$

It is easy to verify that the second derivative of $p_{e}^{\mathrm{RA}}$ in (A.10) and the second derivative of $p_{m}^{\text {RA }}$ in (A.9) are less than zero. Let the first derivative of $p_{e}^{\mathrm{RA}}$ and the first derivative of $p_{m}^{\text {RA }}$ be equal to zero; then, we obtain the two response functions, which are given by

$$
\begin{aligned}
& p_{e}^{\mathrm{RA}}\left(w^{\mathrm{RA}}, \rho^{\mathrm{RA}}\right)=\frac{2 a b \theta-a \lambda \theta+2 b^{2} w^{R A}}{4 b^{2}-\lambda^{2}}+\frac{3 b \lambda \rho^{R A}+\lambda^{2} w^{R A}+a \lambda}{4 b^{2}-\lambda^{2}}, \\
& p_{m}^{\mathrm{RA}}\left(w^{\mathrm{RA}}, \rho^{\mathrm{RA}}\right)=\frac{2 a b-2 a b \theta+a \lambda \theta}{4 b^{2}-\lambda^{2}}+\frac{2 b^{2} \rho^{\mathrm{RA}}+3 b \lambda w^{\mathrm{RA}}+\lambda^{2} \rho^{\mathrm{RA}}}{4 b^{2}-\lambda^{2}} .
\end{aligned}
$$

Substituting (15), (16), (A.11), and (A.12) into (A.9) and finding the first derivative of $w^{\mathrm{RA}}$ and letting it equal to zero, we can obtain the optimal wholesale price by

$$
w^{\mathrm{RA}}\left(\rho^{\mathrm{RA}}\right)=\frac{\left[8 b^{4} \theta+8 \lambda(1-\theta) b^{3}+\lambda^{3}(1-\theta) b+\lambda^{4} \theta\right] a}{2 b(b+\lambda)(b-\lambda)\left(8 b^{2}+\lambda^{2}\right)}-\frac{\left(-8 b^{4} \lambda+7 b^{2} \lambda^{3}+\lambda^{5}\right) \rho^{\mathrm{RA}}}{2 b(b+\lambda)(b-\lambda)\left(8 b^{2}+\lambda^{2}\right)}
$$

Next, substituting (15), (16), and (A.11)-(A.13) into (A.10) and finding the first derivative of $\rho^{\mathrm{RA}}$ and letting it equal to zero, we can obtain the optimal agency fee by

$$
\rho^{\mathrm{RA} *}=\frac{a}{2\left(8 b^{2}+\lambda^{2}\right)(b+\lambda)(b-\lambda)} K_{1} .
$$

Finally, substituting (A.14) into (A.13), the optimal wholesale price is given by

$$
w^{\mathrm{RA} *}=\frac{a\left[\theta\left(2 b^{2}-\lambda^{2}\right)+b \lambda(1-\theta)\right]}{4 b(b+\lambda)(b-\lambda)} .
$$

Substituting (A.14) and (A.15) into (A.11) and (A.12), the optimal prices are given by

$$
\begin{aligned}
p_{e}^{\mathrm{RA} *} & =\frac{a}{4 b(b+\lambda)(b-\lambda)\left(8 b^{2}+\lambda^{2}\right)} K_{2}, \\
p_{m}^{\mathrm{RA} *} & =\frac{a}{4(b+\lambda)(b-\lambda)\left(8 b^{2}+\lambda^{2}\right)} K_{3} .
\end{aligned}
$$

\section{Proof of Proposition 1}

From (4) and (20), we can obtain $w^{\mathrm{RA} *}-w^{R *}=\left(a\left[\left(2 b^{2}-\right.\right.\right.$ $\left.\left.\left.b \lambda-\lambda^{2}\right) \theta-2 b^{2}+b \lambda+2 \lambda^{2}\right] /(4 b(b-\lambda)(b+\lambda))\right)$. For $4 b(b$ $-\lambda)(b+\lambda)>0$, we only need to analyze the positiveness or negativeness of $f_{1}(\theta)=\left(2 b^{2}-b \lambda-\lambda^{2}\right) \theta-2 b^{2}+b \lambda+2 \lambda^{2}$. We can verify that $2 b^{2}-b \lambda-\lambda^{2}>0$. Let $-2 b^{2}+b \lambda+2 \lambda^{2}$ be equal to zero; for $0<\lambda<b$, we know that $\lambda_{1}=((\sqrt{17}-1) / 4) b$. Furthermore, let $\left(2 b^{2}-b \lambda-\right.$ $\left.\lambda^{2}\right) \theta-2 b^{2}+b \lambda+2 \lambda^{2}$ be equal to zero, and we can obtain $\theta_{1}=\left(\left(2 b^{2}-b \lambda-2 \lambda^{2}\right) /\left(2 b^{2}-b \lambda-\lambda^{2}\right)\right)<1$. Therefore, we can find that if $\lambda_{1} \leq \lambda<b$, then $\theta_{1}<0$; thus, $f_{1}(\theta)>0$, $w^{\mathrm{RA} *}>w^{R *}$. If $0<\lambda<\lambda_{1}$, then $0<\theta_{1}<1$; thus, if $\theta>\theta_{1}$, then $f_{1}(\theta)>0, w^{\mathrm{RA} *}>w^{R *}$; otherwise, if $0<\lambda<\lambda_{1}$ and $0<\theta \leq \theta_{1}$, then $f_{1}(\theta) \leq 0, w^{\mathrm{RA} *} \leq w^{R *}$. Therefore, Proposition 1 is proved.

\section{Proof of Proposition 2}

From (12) and (22), we can obtain $p_{m}^{\mathrm{RA} *}-p_{m}^{A *}=(a[-b(b-$ $\left.\lambda)\left(24 b^{2}-2 b \lambda+\lambda^{2}\right) \theta+3 \lambda^{2}\left(8 b^{2}+\lambda^{2}\right)\right] /(4 b(b-\lambda)(b+\lambda)(8$ $\left.\left.\left.b^{2}+\lambda^{2}\right)\right)\right)$. For $4 b(b-\lambda)(b+\lambda)\left(8 b^{2}+\lambda^{2}\right)>0$, we only need to analyze the positiveness or negativeness of $f_{2}(\theta)=$ $-b(b-\lambda)\left(24 b^{2}-2 b \lambda+\lambda^{2}\right) \theta+3 \lambda^{2}\left(8 b^{2}+\lambda^{2}\right)$. From $f_{2}(\theta)$, we can prove that $-b(b-\lambda)\left(24 b^{2}-2 b \lambda+\lambda^{2}\right)<0$ and $3 \lambda^{2}$ $\left(8 b^{2}+\lambda^{2}\right)>0$. Therefore, let $-b(b-\lambda)\left(24 b^{2}-2 b \lambda+\lambda^{2}\right) \theta+$ $3 \lambda^{2}\left(8 b^{2}+\lambda^{2}\right)$ be equal to zero, and we obtain

$\theta_{2}=\left(3 \lambda^{2}\left(8 b^{2}+\lambda^{2}\right) / b(b-\lambda)\left(24 b^{2}-2 b \lambda+\lambda^{2}\right)\right) . \quad$ Then, solving the value of $\lambda$ from $-b(b-\lambda)\left(24 b^{2}-2 b \lambda+\lambda^{2}\right)$ 
$\theta+3 \lambda^{2}\left(8 b^{2}+\lambda^{2}\right)=0$, i.e., $\quad 24 b^{4}-26 b^{3} \lambda-21 b^{2} \lambda^{2} \quad-b \lambda^{3}-$ $3 \lambda^{4}=0$, for $0<\lambda<b$, we can obtain $\lambda_{2} \approx 0.6043 b$. Therefore, when $\lambda_{2} \leq \lambda<b$, then $24 b^{4}-26 b^{3} \lambda-21 b^{2} \lambda^{2}-b \lambda^{3}-3 \lambda^{4} \leq 0$ and the first derivative of $\lambda$ in $24 b^{4}-26 b^{3} \lambda-21 b^{2} \lambda^{2}-b \lambda^{3}-$ $3 \lambda^{4}$ is less than zero; furthermore, $\theta_{2} \geq 1$; therefore, $p_{m}^{\mathrm{RA} *} \geq p_{m}^{A *}$. When $0<\lambda<\lambda_{2}$, then $24 b^{4}-26 b^{3} \lambda-$ $21 b^{2} \lambda^{2}-b \lambda^{3}-3 \lambda^{4}>0$; furthermore, $\theta_{2}<1$; therefore, if $0<\theta \leq \theta_{2}$, then $p_{m}^{\mathrm{RA} *} \geq p_{m}^{A *}$; if $\theta>\theta_{2}$, then $p_{m}^{\mathrm{RA} *}<p_{m}^{A *}$.

From (5) and (21), we can obtain $p_{e}^{\mathrm{RA} *}-p_{e}^{R *}=(a /(4 b$ $\left.\left.(b-\lambda)(b+\lambda)\left(8 b^{2}+\lambda^{2}\right)\right)\right) \times \quad\left[(b-\lambda)\left(24 b^{3}+2 b \lambda^{2}-\lambda^{3}\right) \theta-\right.$ $\left.3\left(8 b^{2}+\lambda^{2}\right)\left(b^{2}-b \lambda-\lambda^{2}\right)\right]$. For $4 b(b-\lambda)(b+\lambda)\left(8 b^{2}\right.$ $\left.+\lambda^{2}\right)>0$, we only need to analyze the positiveness or negativeness of $f_{3}(\theta)=(b-\lambda)\left(24 b^{3}+2 b \lambda^{2}-\lambda^{3}\right) \theta-3\left(8 b^{2}\right.$ $\left.+\lambda^{2}\right)\left(b^{2}-b \lambda-\lambda^{2}\right)$. Let $\quad(b-\lambda)\left(24 b^{3}+2 b \lambda^{2}-\lambda^{3}\right) \theta-3$ $\left(8 b^{2}+\lambda^{2}\right)\left(b^{2}-b \lambda-\lambda^{2}\right)$ be equal to zero, and we can obtain $\theta_{3}=\left(\left(3\left(8 b^{2}+\lambda^{2}\right)\left(b^{2}-b \lambda-\lambda^{2}\right)\right) /\left((b-\lambda)\left(24 b^{3}+2 b \lambda^{2}-\right.\right.\right.$ $\left.\left.\left.\lambda^{3}\right)\right)\right)$. We can easily obtain that $(b-\lambda)\left(24 b^{3}+2 b \lambda^{2}-\lambda^{3}\right)>0$. For $-3\left(8 b^{2}+\lambda^{2}\right)\left(b^{2}-b \lambda-\lambda^{2}\right)=0$, solving the value of $\lambda$, for $0<\lambda<b$, we can obtain $\lambda=((\sqrt{5}-1) / 2) b$. When $((\sqrt{5}-1) / 2) b \leq \lambda<b$, then $\theta_{3}<0$ and $-3\left(8 b^{2}+\lambda^{2}\right)$ $\left(b^{2}-b \lambda-\lambda^{2}\right)<0$; therefore, $p_{e}^{\mathrm{RA} *} \geq p_{e}^{R *}$. When $0<\lambda<$ $((\sqrt{5}-1) / 2) b$, then $0<\theta_{3}<1$ and $-3\left(8 b^{2}+\lambda^{2}\right)\left(b^{2}-b \lambda\right.$ $\left.-\lambda^{2}\right)>0$; therefore, if $\theta_{3} \leq \theta<1$, then $p_{e}^{\mathrm{RA} *} \geq p_{e}^{R *}$; if $0<\theta<\theta_{3}$, then $p_{e}^{\mathrm{RA} *}<p_{e}^{R *}$. Thus, Proposition 2 is proved.

\section{Proof of Proposition 3}

From (11) and (19), we can obtain $\rho^{\mathrm{RA} *}-\rho^{A *}=(a[-b(b-$ $\left.\lambda)\left(8 b^{2}+2 b \lambda+3 \lambda^{2}\right) \theta+\lambda^{2} \quad\left(8 b^{2}+\lambda^{2}\right)\right] /(2 b(b-\lambda)(b+\lambda)(8$ $\left.\left.\left.b^{2}+\lambda^{2}\right)\right)\right)$. For $2 b(b-\lambda)(b+\lambda)\left(8 b^{2}+\lambda^{2}\right)>0$, we only need to analyze the positiveness or negativeness of $f_{4}(\theta)=-b(b-\lambda)\left(8 b^{2}+2 b \lambda+3 \lambda^{2}\right) \theta+\lambda^{2}\left(8 b^{2}+\lambda^{2}\right)$. From $f_{4}(\theta)$, we know that $-b(b-\lambda)\left(8 b^{2}+2 b \lambda+3 \lambda^{2}\right)<0$ and $\lambda^{2}\left(8 b^{2}+\lambda^{2}\right)>0$. Therefore, let $-b(b-\lambda)\left(8 b^{2}+2 b \lambda+\right.$ $\left.3 \lambda^{2}\right) \theta+\lambda^{2}\left(8 b^{2}+\lambda^{2}\right)$ be equal to zero, and we can obtain $\theta_{4}=\left(\lambda^{2}\left(8 b^{2}+\lambda^{2}\right) /\left(b(b-\lambda)\left(8 b^{2}+2 b \lambda+3 \lambda^{2}\right)\right)\right)$. Then, we can compute the value of $\lambda$ from $b(b-\lambda)\left(8 b^{2}+2 b \lambda+\right.$ $\left.3 \lambda^{2}\right)-\lambda^{2}\left(8 b^{2}+\lambda^{2}\right)=0, \quad$ i.e., $\quad(\lambda+2 b)\left(4 b^{3}-5 b^{2} \lambda-b \lambda^{2}\right.$ $\left.-\lambda^{3}\right)=0$. For $0<\lambda<b$, we can obtain $\lambda_{3} \approx 0.6570 b$. Therefore, when $\lambda_{3} \leq \lambda<b$, then $4 b^{3}-5 b^{2} \lambda-b \lambda^{2}-\lambda^{3} \leq 0$ and the first derivative of $\lambda$ in $4 b^{3}-5 b^{2} \lambda-b \lambda^{2}-\lambda^{3}$ is less than zero; furthermore, $\theta_{4} \geq 1$; therefore, $\rho^{\mathrm{RA} *} \geq \rho^{A *}$. When $0<\lambda<\lambda_{3}$, then $4 b^{3}-5 b^{2} \lambda-b \lambda^{2}-\lambda^{3}>0$; furthermore, $\theta_{4}<1$; therefore, if $0<\theta \leq \theta_{4}$, then $\rho^{\mathrm{RA} *} \geq \rho^{A *}$; if $\theta>\theta_{4}$, then $\rho^{\mathrm{RA} *}<\rho^{A *}$. Thus, Proposition 3 is proved.

\section{Proof of Proposition 4}

From (6), (7), (13), and (14), we know that $\Pi_{M}^{R *}-\Pi_{M}^{A *}=$ $\left(a^{2} / 8 b\right)-\left(a^{2} / 16 b\right)=\left(a^{2} / 16 b\right)>0$ and $\Pi_{\mathrm{ER}}^{A *}-\prod_{\mathrm{ER}}^{R *}=\left(a^{2} / 8\right.$ $b)-\left(a^{2} / 16 b\right)=\left(a^{2} / 16 b\right)>0$, so we can easily prove Proposition 4 .

\section{Proof of Proposition 5}

From (6) and (23), we can obtain $\Pi_{M}^{\mathrm{RA} *}-\Pi_{M}^{R *}=$ $\left(a^{2}\left(A_{1} \theta^{2}+B_{1} \theta+C_{1}\right) /\left(16 b(b-\lambda)(b+\lambda)\left(8 b^{2}+\lambda^{2}\right)^{2}\right)\right)$. For $16 b(b-\lambda)(b+\lambda)\left(8 b^{2}+\lambda^{2}\right)^{2}>0$, we only need to analyze the positiveness or negativeness of $f_{5}(\theta)=A_{1} \theta^{2}+B_{1} \theta+C_{1}$. For $A_{1}=(b-\lambda)(2 b+\lambda) \times\left(96 b^{4}-32 b^{3} \lambda+34 b^{2} \lambda^{2}-b \lambda^{3}-\right.$ $\left.\lambda^{4}\right)>0, B_{1}=-2 b(b-\lambda)(2 b-\lambda)(4 b+\lambda)\left(8 b^{2}+\lambda^{2}\right)<0$, and $C_{1}=-(b+\sqrt{2} \lambda)(b-\sqrt{2} \lambda)\left(8 b^{2}+\lambda^{2}\right)^{2}$. Therefore, first, we should discuss the positiveness or negativeness value of $C_{1}$. If $C_{1}>0$, then $\lambda<(\sqrt{2} / 2) b$; if $C_{1}<0$, then $\lambda>(\sqrt{2} / 2) b$. Second, we should determine whether $B_{1}^{2}-4 A_{1} C_{1}$ is positiveness or negativeness. We can obtain $\lambda_{4} \approx 0.7216 b$ from $B_{1}^{2}-4 A_{1} C_{1}=0$. Combining the result of $C_{1}$, we know that if $\lambda_{4} \leq \lambda<b$, then $C_{1}>0$ and $B_{1}^{2}-4 A_{1} C_{1} \leq 0$; if $(\sqrt{2} / 2) b<\lambda<\lambda_{4}$, then $C_{1}>0$ and $B_{1}^{2}-4 A_{1} C_{1}>0$; if $0<\lambda \leq(\sqrt{2} / 2) b$, then $C_{1}<0$ and $B_{1}^{2}-4 A_{1} C_{1}>0$. Third, when $B_{1}^{2}-4 A_{1} C_{1}>0$, we should discuss the value of $\theta$. From $f_{5}(\theta)=0$, we can obtain $\theta_{5}=-\left(\left(B_{1}-\sqrt{B_{1}^{2}-4 A_{1} C_{1}}\right) / 2 A_{1}\right)$ and $\theta_{6}=-\left(\left(B_{1}+\sqrt{B_{1}^{2}-4 A_{1} C_{1}}\right) / 2 A_{1}\right)$. It is obvious that $\theta_{6}<\theta_{5}$. Then, we compare $\theta_{5}$ with 1 . Because $1-\theta_{5}=\left(\left(2 A_{1}+B_{1}-\sqrt{B_{1}^{2}-4 A_{1} B_{1}}\right) / 2 A_{1}\right)$, we can compare them by discussing $\left(2 A_{1}+B_{1}-\sqrt{B_{1}^{2}-4 A_{1} B_{1}}\right)\left(2 A_{1}+B_{1}+\right.$ $\left.\sqrt{B_{1}^{2}-4 A_{1} B_{1}}\right)=4\left(A_{1}+B_{1}+C_{1}\right)$. However, $A_{1}+B_{1}+C_{1}=$ $84 b^{4} \lambda^{2}-6 b^{2} \lambda^{4}+3 \lambda^{6}>0 \quad$ and $\quad 2 A_{1}+B_{1}=2(b-\lambda)$ $\times\left(256 b^{5}+16 b^{4} \lambda+36 b^{3} \lambda^{2}+30 b^{2} \lambda^{3}-4 b \lambda^{4}-\lambda^{5}\right)>0$, so $\left(\left(2 A_{1}+B_{1}-\sqrt{B_{1}^{2}-4 A_{1} B_{1}}\right) / 2 A_{1}\right)>0$, i.e., $\theta_{5}<1$. Finally, combining the above analyses, we can obtain that if $\lambda_{4} \leq \lambda<b$, then $\Pi_{M}^{\mathrm{RA} *} \geq \Pi_{M}^{R *}$. If $(\sqrt{2} / 2) b<\lambda<\lambda_{4}$, then $C_{1}>0$ and $B_{1}^{2}-4 A_{1} C_{1}>0$, and we know $0<\theta_{6}<\theta_{5}<1$. Therefore, if $(\sqrt{2} / 2) b<\lambda<\lambda_{4}$ and $0<\theta \leq \theta_{6}$, then $\Pi_{M}^{\mathrm{RA} *} \geq \Pi_{M}^{R *}$; if $(\sqrt{2} / 2) b<\lambda<\lambda_{4}$ and $\theta_{6}<\theta<\theta_{5}$, then $\Pi_{M}^{\mathrm{RA} *}<\Pi_{M}^{R *}$; and if $\theta_{5} \leq \theta<1$, then $\Pi_{M}^{\mathrm{RA} *} \geq \Pi_{M}^{R *}$. If $0<\lambda \leq(\sqrt{2} / 2) b$, then $C_{1}<0$ and $B_{1}^{2}-4 A_{1} C_{1}>0$, and we know that $\theta_{6}<0$ and $\theta_{5}<1$. Therefore, if $0<\lambda \leq(\sqrt{2} / 2) b$ and $0<\theta<\theta_{5}$, then $\Pi_{M}^{\mathrm{RA} *}<\Pi_{M}^{R *}$; if $\theta_{5} \leq \theta<1$, then $\Pi_{M}^{\mathrm{RA} *} \geq \Pi_{M}^{R *}$.

\section{Proof of Proposition 6}

From (14) and (24), we can obtain $\Pi_{\mathrm{ER}}^{\mathrm{RA} *}-\Pi_{\mathrm{ER}}^{A *}=$ $\left(a^{2}\left(A_{2} \theta^{2}+B_{2} \theta+C_{2}\right) /\left(8 b(b-\lambda)(b+\lambda)\left(8 b^{2}+\lambda^{2}\right)\right)\right)$. For $8 b(b-\lambda)(b+\lambda)\left(8 b^{2}+\lambda^{2}\right)>0$, we only need to analyze the positiveness or negativeness of $f_{6}(\theta)=A_{2} \theta^{2}+B_{2} \theta+C_{2}$. For $\quad A_{2}=(b-\lambda)\left(12 b^{3}+5 b \lambda^{2}-\lambda^{3}\right)>0, \quad B_{2}=-2 b(b-\lambda)$ $\left(8 b^{2}+2 b \lambda+3 \lambda^{2}\right)<0, C_{2}=\lambda^{2}\left(8 b^{2}+\lambda^{2}\right)>0$. First, we should determine whether $B_{2}^{2}-4 A_{2} C_{2}$ is positiveness or negativeness. We can obtain $\lambda_{5} \approx 0.6064 b$ from $B_{2}^{2}-4 A_{2} C_{2}=0$. Therefore, if $\lambda_{5} \leq \lambda<b$, then $B_{2}^{2}-4 A_{2} C_{2} \leq 0$; if $0<\lambda<\lambda_{5}$, then $B_{2}^{2}-4 A_{2} C_{2}>0$. Second, when $B_{2}^{2}-4 A_{2} C_{2}>0$, we should discuss the value of $\theta$. From $f_{6}(\theta)=0$, we can obtain $\theta_{7}=-\left(\left(B_{2}-\sqrt{B_{2}^{2}-4 A_{2} C_{2}}\right) / 2 A_{2}\right) \quad$ and $\theta_{8}=-\left(\left(B_{2}+\right.\right.$ $\left.\left.\sqrt{B_{2}^{2}-4 A_{2} C_{2}}\right) / 2 A_{2}\right)$. It is obvious that $0<\theta_{8}<\theta_{7}$. Then, we compare $\theta_{7}$ with 1 . Because $1-\theta_{7}=\left(\left(2 A_{2}+B_{2}\right.\right.$ $\left.\left.-\sqrt{B_{2}^{2}-4 A_{2} B_{2}}\right) / 2 A_{2}\right)$, we can compare them by discussing $\left(2 A_{2}+B_{2}-\sqrt{B_{2}^{2}-4 A_{2} B_{2}}\right) \quad\left(2 A_{2}+B_{2}+\sqrt{B_{2}^{2}-4 A_{2} B_{2}}\right)=4$ 
$\left(A_{2}+B_{2}+C_{2}\right)$. However, $A_{2}+B_{2}+C_{2}=-4 b^{4}+11 b^{2} \lambda^{2}$ $+2 \lambda^{4}$, for $0<\lambda<b$, and we can obtain $\lambda=$ $((\sqrt{3 \sqrt{17}-11}) / 2) b$ from $-4 b^{4}+11 b^{2} \lambda^{2}+2 \lambda^{4}=0$. Therefore, if $\lambda \leq((\sqrt{3 \sqrt{17}-11}) / 2) b$, then $\theta_{7}>1$; furthermore, $0<\theta_{8}<1<\theta_{7}$; if $\lambda>((\sqrt{3 \sqrt{17}-11}) / 2) b$, then $\theta_{7}<1$; furthermore, $0<\theta_{8}<\theta_{7}<1$. Finally, combining the above analyses, we can obtain that if $\lambda_{5} \leq \lambda<b$, then $B_{2}^{2}-4 A_{2} C_{2} \leq 0$, so $\Pi_{\mathrm{ER}}^{\mathrm{RA} *} \geq \Pi_{\mathrm{ER}}^{A *}$. If $((\sqrt{3 \sqrt{17}-11}) / 2) b<\lambda<\lambda_{5}$, then $B_{2}^{2}-$ $4 A_{2} C_{2}>0$ and $0<\theta_{8}<\theta_{7}<1$; furthermore, if $0<\theta \leq \theta_{8}$, then $\Pi_{\mathrm{ER}}^{\mathrm{RA} *} \geq \Pi_{\mathrm{ER}}^{A *}$; if $\theta_{8}<\theta<\theta_{7}$, then $\Pi_{\mathrm{ER}}^{\mathrm{RA} *}<\Pi_{\mathrm{ER}}^{A *}$; and if $\theta_{7} \leq \theta<1$, then $\Pi_{\mathrm{ER}}^{\mathrm{RA} *} \geq \Pi_{\mathrm{ER}}^{A *}$. If $0<\lambda \leq((\sqrt{3 \sqrt{17}-11}) / 2) b$, then $B_{2}^{2}-$ $4 A_{2} C_{2}>0$ and $0<\theta_{8}<1<\theta_{7}$; therefore, in addition, if $0<\theta \leq \theta_{8}$, then $\Pi_{\mathrm{ER}}^{\mathrm{RA} *} \geq \Pi_{\mathrm{ER}}^{A *}$; if $\theta_{8}<\theta<1$, then $\Pi_{\mathrm{ER}}^{\mathrm{RA} *}<\Pi_{\mathrm{ER}}^{A *}$.

\section{Proof of Proposition 7}

From Propositions 5 and 6 , we know that $\lambda_{4}>\lambda_{5}$ and $\theta_{6}<\theta_{8}<\theta_{5}<\theta_{7}$, so Proposition 7 is easy to be proved.

\section{Data Availability}

All related data are included within the article.

\section{Conflicts of Interest}

The authors declare that there are no conflicts of interest regarding the publication of this article.

\section{Acknowledgments}

This study was supported by the National Natural Science Foundation Council of China under project nos. 71862035 and 71862034, the Yunnan Fundamental Research Project under grant no. 2019FB085, and the 21st Yunnan Young and Middle-Aged Academic and Technical Leaders Reserve Personnel Training Program under grant no. 2019HB030.

\section{References}

[1] R. Research, "Online retailing: Britain, Europe, US and Canada 2017. Centre for retail research," 2017, https:// wwwretailresearchorg/onlineretailingphp.

[2] A. Research, "BRICS national electronic commerce research report," 2017, https://wwwaliresearchcom/blog/article/detail/ id/21376html.

[3] V. Abhishek, K. Jerath, and Z. J. Zhang, "Agency selling or reselling? Channel Structures in electronic retailing," Management Science, vol. 62, no. 8, pp. 2259-2280, 2016.

[4] M. B. Taobao Seo, "A guide to one of the world's largest consumer marketplaces. Search engine watch," 2012, https:// searchenginewatchcom/sew/how-to/2200749/taobao-seo-aguide-to-one-of-the-worlds-largst-consumer-marketplaces.

[5] B. Jiang, K. Jerath, and K. Srinivasan, "Firm strategies in the "mid tail" of platform-based retailing," Marketing Science, vol. 30, no. 5, pp. 757-775, 2011.

[6] R. Wischenbart, "Global eBook. A report on market trends and developments," Update Fall 2014, Rüdiger Wischenbart Content and Consulting, Berlin, Germany, 2014.
[7] N. Davis, "Reselling digital music: is there a digital first sale doctrine," Loyola of Los Angeles Entertainment Law Review, vol. 29, p. 363, 2008.

[8] C. Liu, B.-L. Xie, and S. An, "Self-pickup or door-to-door: the impact of self-pickup service on e-tailers," Journal of Interdisciplinary Mathematics, vol. 20, no. 6-7, pp. 1557-1562, 2017.

[9] Z. Song, S. He, and B. An, "Decision and coordination in a dual-channel three-layered green supply chain," Symmetry, vol. 10, no. 11, p. 549, 2018.

[10] S. Saha and I. Nielsen, "Strategic integration decision under supply chain competition in the presence of online channel," Symmetry, vol. 13, no. 1, p. 58, 2021.

[11] Y. Cheng, B. Li, and Z. Li, "Analysis of the optimal threshold policy of the E-tailer with mixture strategy in E-fulfillment," International Journal of Information Systems and Supply Chain Management, vol. 9, no. 2, pp. 21-34, 2016.

[12] H. Xu, Y. Gong, C. Chu, and J. Zhang, "Dynamic lot-sizing models for retailers with online channels," International Journal of Production Economics, vol. 183, pp. 171-184, 2017.

[13] R. Yan and Z. Cao, "Product returns, asymmetric information, and firm performance," International Journal of Production Economics, vol. 185, no. 5, pp. 211-222, 2017.

[14] W. K. Chiang and Y. Feng, "Retailer or e-tailer? Strategic pricing and economic-lot-size decisions in a competitive supply chain with drop-shipping," Journal of the Operational Research Society, vol. 61, no. 11, pp. 1645-1653, 2017.

[15] D.-Q. Yao, H. Kurata, and S. K. Mukhopadhyay, "Incentives to reliable order fulfillment for an Internet drop-shipping supply chain," International Journal of Production Economics, vol. 113, no. 1, pp. 324-334, 2008.

[16] X. Gan, S. P. Sethi, and J. Zhou, "Commitment-penalty contracts in drop-shipping supply chains with asymmetric demand information," European Journal of Operational Research, vol. 204, no. 3, pp. 449-462, 2010.

[17] J. Razmi, A. Hassani, and R. Babazadeh, "A hybrid fuzzy biobjective delivery planning model for leagile e-tailing under uncertainty," International Journal of Management Science and Engineering Management, vol. 10, no. 1, pp. 62-72, 2015.

[18] Z. H. Dennis, T. Cheong, and D. Sun, "Impact of supply chain power and drop-shipping on a manufacturer's optimal distribution channel strategy," European Journal of Operational Research, vol. 259, no. 2, pp. 554-563, 2017.

[19] J. P. Johnson, "The agency model and MFN clauses," The Review of Economic Studies, vol. 84, no. 3, pp. 1151-1185, 2017.

[20] A. Hagiu and J. Wright, "Sharing revenue and control," 2016, https://profilenusedusg/fass/ecsjkdw/hybrid\%20with\%20partial \%20delegation\%20sept2016pdf.

[21] J. P. Johnson, "The agency and wholesale models in electronic content markets," International Journal of Industrial Organization, vol. 69, Article ID 102581, 2020.

[22] L. Ling, X. Guo, and C. Yang, "Opening the online marketplace: an examination of hotel pricing and travel agency on-line distribution of rooms," Tourism Management, vol. 45, pp. 234-243, 2014.

[23] L. Hao, M. Fan, and M. Fan, "An analysis of pricing models in the electronic book market," MIS Quarterly, vol. 38, no. 4, pp. 1017-1032, 2014.

[24] B. De los Santos and M. R. Wildenbeest, "E-book pricing and vertical restraints," Quantitative Marketing and Economics, vol. 15, no. 2, pp. 85-122, 2017.

[25] Y. Tan and J. E. Carrillo, "Strategic analysis of the agency model for digital goods," Production and Operations Management, vol. 26, no. 4, pp. 724-741, 2017. 
[26] Y. Tan, J. E. Carrillo, and H. K. Cheng, "The agency model for digital goods," Decision Sciences, vol. 47, no. 4, pp. 628-660, 2016.

[27] Q. Lu, V. Shi, and J. Huang, "Who benefit from agency model: a strategic analysis of pricing models in distribution channels of physical books and e-books," European Journal of Operational Research, vol. 264, no. 3, pp. 1074-1091, 2018.

[28] Y. Kwark, J. Chen, J. Chen, and S. Raghunathan, "Platform or wholesale? A strategic tool for online retailers to benefit from third-party information," MIS Quarterly, vol. 41, no. 3, pp. 763-785, 2017.

[29] A. Hagiu and J. Wright, "Marketplace or reseller?" Management Science, vol. 61, no. 1, pp. 184-203, 2015.

[30] D. C. Dantas, S. Taboubi, and G. Zaccour, "Which business model for e-book pricing?” Economics Letters, vol. 125, no. 1, pp. 126-129, 2014.

[31] S. Zhang and J. Zhang, "Agency selling or reselling: E-tailer information sharing with supplier offline entry," European Journal of Operational Research, vol. 280, no. 1, pp. 134-151, 2020.

[32] L. Tian, A. J. Vakharia, Y. R. Tan, and Y. Xu, "Marketplace, reseller, or hybrid: strategic analysis of an emerging E-commerce model," Production and Operations Management, vol. 27, no. 8, pp. 1595-1610, 2018.

[33] Y. Zennyo, "Strategic contracting and hybrid use of agency and wholesale contracts in e-commerce platforms," European Journal of Operational Research, vol. 281, no. 1, pp. 231-239, 2020.

[34] F. Ye, L. Zhang, and Y. Li, "Strategic choice of sales channel and business model for the hotel supply chain," Journal of Retailing, vol. 94, no. 1, pp. 33-44, 2018.

[35] C. Zhu and Z. Yao, "Comparison between the agency and wholesale model under the e-book duopoly market," Electronic Commerce Research, vol. 18, no. 8, pp. 1-25, 2017.

[36] X. Qin, Z. Liu, and L. Tian, "The optimal combination between selling mode and logistics service strategy in an e-commerce market," European Journal of Operational Research, vol. 289, no. 2, pp. 639-651, 2020.

[37] Y. Feng, Y. R. Tan, Y. Duan, and Y. Bai, "Strategies analysis of luxury fashion rental platform in sharing economy," Transportation Research Part E: Logistics and Transportation Review, vol. 142, Article ID 102065, 2020.

[38] X. Pu, S. Sun, and J. Shao, "Direct selling, reselling, or agency selling? Manufacturer's online distribution strategies and their impact," International Journal of Electronic Commerce, vol. 24, no. 2, pp. 232-254, 2020. 